\title{
A Preliminary Report on Plasma Insulin Concentrations on Japanese Shorthorn and Japanese Black Cattle from Birth to 8 Weeks of Age
}

\author{
Motoaki Kosugryama, Akira Katada*, Takeaki KıKuchI \\ and Tadashi KYumA \\ Livestock Division, Tohoku National Agricultural Experiment Station, Morioka-shi 020-01 \\ (Received October 2, 1974)
}

TRENKLE ${ }^{1)}$ described in the review that basal plasma insulin levels were $15-50 \mu \mathrm{U} / \mathrm{ml}$ in cattle. Young et al. ${ }^{2)}$ found no significant relationship between insulin level and age. IRviN and TRENKLE ${ }^{3)}$ reported that plasma insulin levels could not be related to age or breed in cattle from 18 to 371 days of age. At 371 days, steers had higher levels of plasma insulin than heifers. These increased levels in the steers were reasonably related to the consumption of finishing rations rather than age or sex.

At present, however, no report is available about plasma insulin levels of Japanese Shorthorn and Japanese Black Cattle. The purpose of this study was not obtain basic data of plasma insulin concentrations in calves of Japanese Shorthorn and Japanese Black Cattle and to see whether the results obtained in other breeds can be held in these Japanese breeds or not. In this study, young sucking calves which were not fed with rations were used to investigate the breed difference of plasma insulin levels, as it was known that insulin levels of adult calves were influenced by feeding rations ${ }^{3)}$.

\section{Materials and Methods}

\section{Animals}

Two male and three female calves of Japanese Shorthorn and five female calves of Japanese Black Cattle were used in this study. All calves were nursed by their mothers during first eight weeks after birth. Mothers of Japanese Shorthorn were pastured without giving concentrate. Mothers of Japanexe Black Cattle were maintained indoors. The larger mothers were fed with roughage only, but the smaller ones were fed with roughage and some concentrate.

In Japanese Shorthorn, the plasma samples at 0 week of age were collected after sucking of colostrum and within 24 hours after birth. Then, other samples were collected at 1, 2, 3, 4, 6 and 8 weeks of age (on Thursday) from the same group of calves. The number of female calves was two at 3 and 8 weeks of age (Fig. 1, left side).

Plasma collection

In Japanese Black Cattle, the plasma samples at 0 week of age were collected at 24 hours after the first sucking of colostrum. Then, other samples were collected at 7 th day ( 1 week of age) and 14th day (2 weeks of age) after birth and at 4,6 and 8 weeks of age (on Thursday) from the same group of calves. The number of calves was four at 4 and 8 weeks of age and two at 6

* Present Adress: Tropical Agricultural Research Center, Tokyo, Japan. 

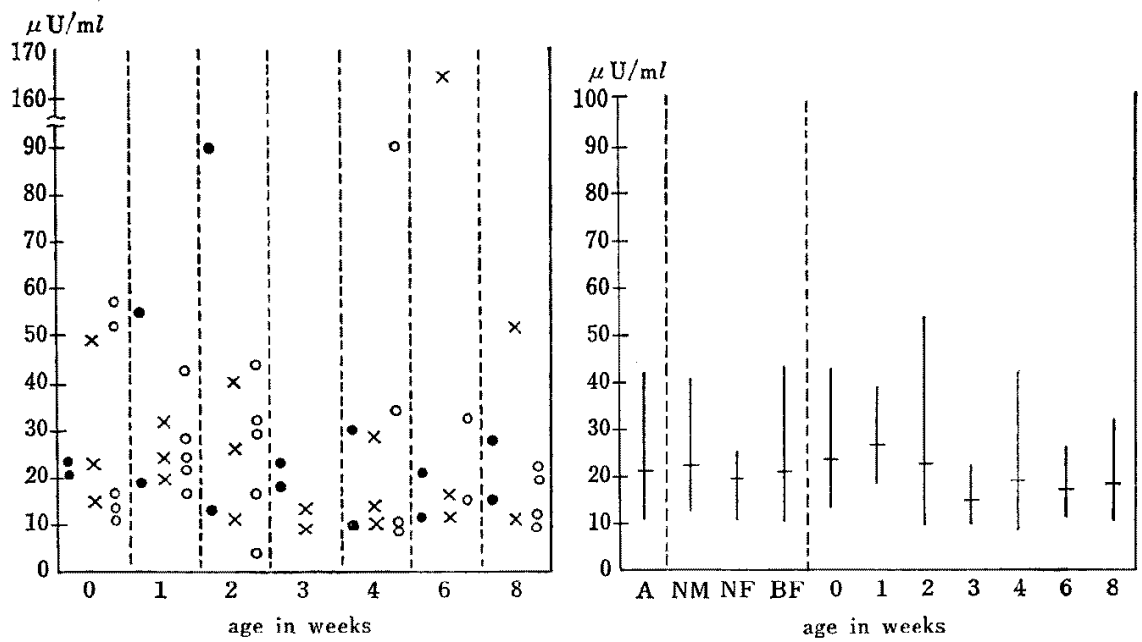

A : All calves

-, NM: Japanese Shorthorn, male calves

$x, N F$ : Japanese Shorthorn, female calves

$\circ$, B F: Japanese Black Cattle, female calves

$t$ : Mean with standard deviation

Fig. 1. The plasma insulin concentrations in male and female calves of Japanese Shorthorn and in female calves of Japanese Black Cattle from 0 to 8 weeks of age

weeks of age (Fig. 1, left side).

The time of blood sampling of both breeds was 10:30 a.m. except 0 week of age.

Blood plasma was separated from the whole blood sample as fast as possible and stored at $-20^{\circ} \mathrm{C}$ until insulin assay.

\section{Radioimmunoassay}

The plasma insulin was determined by radioimmunoassay using Insulin Immunoassay Kit (RCC, Amersham), based on the method of HaLes and RandLE" .

Statistical analysis

All data were transformed into natural logarithms. The mean and standard deviation were calculated from these transformed data after adequate test of normality ${ }^{5}$.

Then, the transformed data were divided into three lots (male and female calves of Japanese Shorthorn and female calves of Japanese Black Cattle). The means and standard deviations of each lot were calculated from these transformed data after adequate test of normalitys) of the data of each lot and after the analysis of variance ${ }^{6)}$ for difference among lots. In the same way, the transformed data were divided into seven ages lots and the means and standard deviations were calculated.

All the means and standard deviations calculated from the data transformed into logarithms were expressed in the regular forms after adverse transformation.

\section{Results and Discussion}

The plasma insulin concentrations in male and female calves of Japanese Sorthorn and in female calves of Japanese Black Cattle from 0 to 8 weeks of age are shown in Fig. 1 (left side). These results were well consistent with the result in the review of TRENKLE ${ }^{1)}$ that basal plasma 


\section{Kosugiyama, Katada, Kikuchi and Kyuma}

insulin levels were $15-50 \mu \mathrm{U} / \mathrm{m} l$ in cattle, although in this study three exceptionally high concentrations of $90 \mu \mathrm{U} / \mathrm{m} l$ or over were obtained. Among the data of individual calves, any distinct discrepancy was not observed.

The means with standard deviations of plasma insulin concentrations in all calves, male and female calves of Japanese Shorthorn and female calves of Japanese Black Cattle and in each age are shown in Fig. 1 (right side). The distribution of the data of female calves of Japanese Shorthorn and the distribution of the data at 6 weeks of age were not normal $(P<0.05)$. They showed, however, normal distributions after excluding the highest value $(165 \mu \mathrm{U} / \mathrm{ml})$, and hence the means and standard deviations were calculated excluding that value.

As the result of the analysis of variance, there was no difference among the means of plasma insulin concentrations of male and female calves of Japanese Shorthorn and female calves of Japanese Black Cattle. There was, also, no difference among the means of plasma insulin concentrations of seven age lots.

The results of this study indicated that plasma insulin levels could not be related to age, breed or sex from 0 to 8 weeks of age, although the number of experimental sample was very small.

The authors wish to express our appreciation to Dr. Tsuneyuki Tsuda, Professor of Tohoku University and Dr. Kaichi Ambo, Assistant Professor of Tohoku University for their kind guidance of insulin radioimmunoassay and review of this paper. Also the authors wish to acknowledge the advice and reading of the manuscript by Mr. Shoichi HonzaWA, Chief of this division.

\section{Refferences}

1) Trenkie, A., J Dairy Sci 55: 1200-1211. 1972.

2) Young, J. W., E. O. Otchere, A. Trenkle, and N. L. Jacobson, J Nutr 100: 1267-1274. 1970.

3) Irvin, R., and A. Trenkle, J Anim Sci 32: 292-295. 1970.

4) Hales, C. N., and P. J. Randle, Biochem J 88: 137-146. 1963.

5) Kishine, T., (1966) Tokeigaku (in Japanese) 1 ed. 350-352. Yokendo. Tokyo.

6) Terada, K., (1951) Suisoku Tokeiho (in Japanese) 1 ed. 86-89. Asakura-shoten. Tokyo. 